\title{
The spatial hierarchy of technological change and economic development in Europe
}

\author{
Bart Verspagen
}

Received: 23 January 2009 / Accepted: 23 January 2009 / Published online: 17 February 2009

(C) The Author(s) 2009. This article is published with open access at Springerlink.com

\begin{abstract}
This paper discusses the possibility of a spatial hierarchy of innovation and growth dynamics in Europe. A spatial hierarchy is understood as a geographical clustering of regions, where important differences exist in terms of innovation and growth dynamics between the clusters. The literature on regional growth and innovation is briefly scanned. After this, a database on European regional growth and innovation dynamics is presented. Spatial correlation analysis and spatial principal components analysis are used to explore the possibility of a spatial hierarchy in Europe. The results point to a hierarchy consisting of four groups: South Europe, East Europe, and two groups in West and North Europe. Growth and innovation performance in these clusters are discussed, and some policy conclusions are drawn.
\end{abstract}

JEL Classification $\mathrm{O} 33 \cdot \mathrm{R} 3$

\section{Introduction}

Regional policy is becoming more and more important in the EU, especially because of the eastward enlargement of the Union. The challenge of regional cohesion, since long one of the key policy aims at the European level, has become much larger now that the EU has been enlarged to 27 member states, and all these new members have relatively low GDP per capita levels, as well as economic systems that are still much influenced by their communist past.

B. Verspagen $(\varangle)$

Department of Economics, Maastricht University and UNU-Merit,

PO Box 616, 6200 MD Maastricht, The Netherlands

e-mail: b.verspagen@algec.unimaas.nl

URL: http://www.verspagen.nl 
The importance of cohesion in regional policies at the EU level stems from the basic idea that, with a laissez-faire attitude by policymakers, regional income levels and other indicators of development, would show a (too) high level of disparity. This immediately underlines the importance of identifying the factors that underlie disparity (or the lack of it) in regional development. It is the aim of this paper to present descriptive evidence with regard to one of these factors, i.e., technological change and innovation. Specifically, what the paper sets out to do is to investigate in a quantitative and empirical way how patterns of technological change and innovation at the regional level in Europe are correlated with regional economic development. The paper also contributes, albeit in a modest way, to the theoretical interpretation of such a correlation pattern.

Innovation has since long been suggested as one of the key factors in regional growth (e.g., Fagerberg and Verspagen 1996), and the topic therefore plays a large role in discussions on regional cohesion, although perhaps this is not always matched by the policy practice of the so-called European Structural Funds (which are still much aimed at infrastructure). Innovation has the potential to both increase (by differential rates of innovation) and decrease (by diffusion of knowledge) regional income differentials. In addition, because innovation and knowledge flows are found to be spatially concentrated, they have the potential to create spatial patterns in which high and low growth are separated geographically (e.g., Storper and Walker 1989). I propose to use, in a loose sense, the term spatial hierarchy for such a pattern of geographically correlated differences in economic growth and innovation.

Innovation is far from being the only factor that may contribute to regional divergence or convergence. Traditionally, economic theory has identified either factor movements (migration of labour or international capital markets) or international/interregional trade as processes that will lead to convergence of factor prices, and hence income levels. Diffusion of technological knowledge may be seen as a factor that is interwoven with this, as knowledge is often embodied in people, goods and capital. Hence much of the early work on regional growth dynamics (e.g., Barro and Sala-i-Martin 1991) focused on measuring the speed of convergence, which turned out to be somewhat lower than expected on the basis of the theory. Regional differences of innovation and factors impeding the diffusion of knowledge were immediately among the factors identified to be behind slow convergence (e.g., Fagerberg and Verspagen 1996), but there are also other processes that contribute to this.

One view is that, at least in Europe and despite the decades-long process of European integration, fragmentation of factor and goods markets is still considerable. Such fragmentation may exist in the form of non-custom barriers (e.g., related to the non-tradable nature of some goods, or regulation), a low mobility of the labour force (e.g., segmented labour markets), and barriers to the diffusion of knowledge. An overview of these factors is provided in Cuadrado-Roura (2001). Another view, commonly associated with the so-called new economic geography (Krugman 1991), is that because of spatial increasing returns, increasing market integration will lead to divergence rather than convergence (e.g., Krugman 1993). The latter view is similar to the perspective we will take on technology and regional development section in this paper (see also Caniëls and Verspagen 2001; Fagerberg et al. 1997). 
Within this broad debate on European regional disparities, this paper singles out technology and innovation as the factor on which focus is placed. The analysis will be aimed at a descriptive overview of the spatial patterns of innovation and growth at the regional level in Europe. The specific research questions that will be asked are, first, whether any spatial concentration can be observed in growth rates and the potential variables that determine them across the European geography; and second, whether there is any indication that this has led to a spatial hierarchy in Europe that reflects the specific advantages that some parts of the EU have over others in generating economic welfare from investment in technological change.

Although there is much work on innovation and economic growth among European regions (Fagerberg et al. 1997; Bottazzi and Peri 2003, to name just a few), the evidence on the overall spatial patterns of interaction between the two phenomena is still scarce. It is the aim of this paper to provide such an overview, by using a concrete dataset covering a broad range of 30 variables, and a set of 154 regions covering the EU-25, as well as a range of impressionistic quantitative techniques. The perspective will be very much explicitly a spatial one, i.e., the importance of the role of geographical space is acknowledged in the empirical methods and the data collection process. Although there is a need for it, the paper does not aim to develop or apply a theoretical framework that can precisely outline and identify the causal relationships between technology, economic growth and the factor that (jointly) drive them. ${ }^{1}$ Instead, the paper takes an explorative empirical perspective.

The paper is organized as follows. Section 2 provides a brief overview of the theoretical work on technology, economic growth and regional disparities in living standards. The aim of this section is not to be complete, but only to outline the main themes of the discussion that this paper wants to address. In Sect. 3, we will explain the geographical classification that is used throughout the analysis, as well as the spatial weighting scheme. Section 4 briefly introduces the data. Section 5 looks at a basic indicator of spatial dependence, i.e., Moran coefficients for spatial correlation, in order to describe the basic tendencies of spatial interaction between our variables. Section 6 provides the final piece of empirical analysis, and uses a combination of spatial principal components analysis and cluster analysis to classify regions. We obtain four groups of regions, which we interpret as the spatial hierarchy of growth and innovation in Europe. Section 7 summarizes and concludes.

\section{Theoretical background}

Technological change is now central in the theory of economic growth. It is recognized as an important driver of productivity growth and the emergence of new products from which consumers derive welfare. The relationship between technological change and economic growth and development can be analyzed from a variety of theoretical perspectives (Verspagen 2004). All of these stress how technological change itself depends not only on the work by scientists and engineers, but also on a wider range

\footnotetext{
${ }^{1}$ The model by Caniëls and Verspagen (2001) can be considered as a first attempt at such a theoretical framework.
} 
of economic and societal factors, including institutions such as intellectual property rights and corporate governance, the working of markets, a range of governmental policies (science and technology policy, innovation policy, macroeconomic policy, competition policy, etc.), historical specificities, etc.

While it is beyond the scope of this contribution to survey these approaches and factors in a detailed way, there is at least one general conclusion that may be derived with regard to the technology economy relationship. This is the tendency for technology to be both a factor of divergence of development levels between parts of the world, and, in other eras or areas, to be a factor of convergence. Convergence results if knowledge diffuses from developed parts of the world to less developed parts, divergence is the result of the developed parts generating more knowledge. Historically, the net balance of this seems to be a sizable heterogeneity in living standards between different parts of the world. This is a relevant phenomenon even between regions in a relatively homogenous set of countries such as Europe: in the dataset of 154 regions that will be used below, the ratio of GDP per capita in the richest and poorest region was 6 in 1995, and it grew to 6.66 in 2002. This is roughly equal to the ratio between GDP per capita in the US and China in 2005.

One of the central mechanisms that makes technology a potentially diverging factor is the property that knowledge itself is an important factor in producing knowledge (Dosi 1988). Thus, those (firms, regions, countries) who already possess an advantageous position in generating technological change for growth, are likely to remain in a good position: knowledge is cumulative, characterized by (dynamic) increasing returns. This phenomenon is potentially counteracted by another characteristic of technology and knowledge, i.e., that it is a non-rival good that may spill over to others than the ones who originally introduce an innovation. In other words, technology may be imitated at lower costs than at which it is introduced. This is a great potential source of (global) welfare, since it greatly increases the potential pay-off of technological change without proportionally increasing the costs of it. ${ }^{2}$ Thus, convergence by means of the diffusion of knowledge will raise both the general level of welfare in the economy, and increase cohesion.

At the macro-level, the beneficial effect of technology imitation and spillovers is seriously hampered by the same phenomenon that causes technology to possess increasing returns: in order to imitate technology, a certain, substantial level of knowledge is required at the end of the imitator (e.g., Abramovitz 1986; Fagerberg 1994). This is recognized in the literature in the notion of absorptive capacity (e.g., Cohen and Levinthal 1989; Criscuolo and Narula 2008), which is considered as a prerequisite for successful technology diffusion. A lack of absorptive capacity may lead to a vicious circle, or low-growth trap (Verspagen 1991), because countries without substantial knowledge about modern technologies will both generate low growth and be unable to benefit from imitation.

Thus, technology spillovers play a central role in processes of divergence and convergence of welfare levels. At the regional level, technology spillovers have an important spatial component, as it has been argued that spillovers do not travel easily

\footnotetext{
2 However, spillovers also pose an incentive problem (Arrow 1962), because threatened imitation discourages investment in technology that is undertaken for private benefits.
} 
over large distances. This is a phenomenon that has been discussed from a wide variety of perspectives, such as business studies (Von Hippel 1994), economic geography (Morgan 2004), and economics (Jaffe et al. 1993). The most often quoted reason for such a tendency of knowledge spillovers to be geographically concentrated, is that knowledge transfer has important tacit dimensions. While certain parts of knowledge may be codified, for example in written materials, other, important parts are embodied in the minds of practitioners, and can only be transferred by face-to-face interaction. Even with jet air travel and the internet, being located in proximate geographical space thus provides important advantages for transmitting and receiving knowledge spillovers (e.g., Johnson et al. 2002).

It is a quite intuitive argument that the local nature of spillovers can lead to geographical hierarchies of economic development and growth, or core-periphery patterns (see, e.g., Martin and Ottaviano 1999, for a formal exposition in the tradition of the new economic geography; Caniëls and Verspagen 2001 for a formal evolutionary approach, or Storper and Walker 1989, for a more appreciative perspective). This may be aggravated by institutional fragmentation in the European innovation system, i.e., national and regional differences in the institutions that influence innovation across Europe, which further inhibit the flow of technological knowledge. The recent EU policy initiative to build a "European Research Area" seems to be motivated by such concerns (Edler et al. 2003).

One factor that is of particular interest to the empirical results that will be presented below, is the role of cities in this process. The literature on urban growth (starting with Jacobs 1969, see also, e.g., Frenken et al. 2007; Glaeser et al. 1992; Henderson 2003) argues that urban environments are particularly conducive to externalities related to the variety of economic activities. The idea here is that a broad range of economic sectors may stimulate productivity growth and innovation in general, and (large) cities typically host such a broad range of activities. Thus, urban environments may be particularly good in generating innovations and absorbing knowledge spillovers. To the extent that urbanization is, in the short and middle run, predetermined in a spatial sense, this view provides another reason why we would observe a limited degree of knowledge diffusion across European space, and associated slow regional convergence.

Fagerberg et al. (1997) have argued that in Europe, the net impact of these factors related to the generation and diffusion of technology and innovation, may have been a diverging influence over the past decades. But the (empirical) work on the spatial dimension of technology spillovers has mainly addressed the (less far-reaching) issue whether spillovers are geographically concentrated or not, and has ignored the consequences of this issue for economic growth rate differentials. This empirical work, at least in economics, is mainly based on patent citations (e.g., Jaffe et al. 1993, for the US, Maurseth and Verspagen 2002; Bottazzi and Peri 2003, both for Europe), and concludes that there is indeed a tendency for spillovers between nearby locations to be more frequent than between far-away places. $^{3}$

\footnotetext{
3 Breschi and Lissoni (2001) raised the possibility that the observation of localized patent citations stems from localized technology transactions, rather than spillovers or externalities proper.
} 
But it is also clear that spillovers, and patent citations, may also occur over large distances, and the work on the geographic concentration of patent citations has not tackled the question of how strong the local and non-local parts of spillover influence growth rates and growth rate differentials. In fact, this literature most often does not even ask the question as to what is the impact of geographically concentrated spillovers on the location of invention or innovation activities. Obviously, if technology transfer is easier over close distances, there is an incentive to locate R\&D (and other innovation related) activities close together in space. But the patent citations literature sees this as something that needs to be controlled for, rather than something that needs to be explained and used as a starting point for further analysis.

The reason for this is that the two phenomena, location of R\&D and technology spillovers as indicated by patent citations, are hard to distinguish from a causal point of view. If $R \& D$ is concentrated (for whatever reason, including spillovers), spillovers will automatically occur over shorter distances, simply because the two parties in the spillover are located close together. Thus, without an exact overview of why R\&D and innovation activities are historically co-located, it is hard to make a clear assessment of causality. Therefore, researchers (following Jaffe et al. 1993) have focused on the question if patent citations (as an indication of spillovers) are more concentrated than could be expected on the basis of the pre-existing pattern of concentration of R\&D. Such a strategy, even if useful for the specific context in which it is used, does not bring us further in terms of assessing the importance of geographically concentrated technology flows for the geography of economic development and growth.

One approach to explore these broader linkages that seems especially popular in policy circles is the idea to apply a large set of innovation indicators and link them together in a composite indicator. This relates quite well to the theoretical argument that innovation is a multi-faceted process that interacts with a broad range of other processes. The so-called European Innovation Scoreboard (e.g., European Commission 2001) is an influential example of such a strategy. But it is one thing to use a broad range of indicators, and quite another thing to link them together into a coherent framework that is consistent with theory. The composite indicators that result from the scoreboards are often arbitrary in the way they link the individual indicators together (Grupp and Mogee 2004).

One possibility to avoid complete arbitrariness is to rely on statistical techniques that summarize the empirical correlations in the data on the various indicators. Such a summary may then be interpreted from a more theoretical point of view, in order to ask the question whether spatial hierarchies in innovation and regional development exist. This is the strategy that this paper follows, and it uses (spatially weighted) factor analysis and cluster analysis as the statistical tools to achieve this goal (Zabala-Iturriagagoitia et al. 2007 use a different statistical technique, but with similar goals, i.e., data envelopment analysis). The strategy used here is related to earlier work on so-called regional convergence clubs (e.g., Fagerberg and Verspagen 1996; Verspagen 1999), but adds a more explicit spatial aspect to the statistical method. 


\section{Regional classification and distance weights}

The regional classification that is used in this paper is based on the commonly used NUTS classification of regions in Europe. ${ }^{4}$ However, we do not use the standard NUTS scheme, but instead opt to create a custom classification, which is based on a mixture between NUTS aggregation levels. We use NUTS level 0 , which is the country level, for Denmark, Estonia, Ireland, Latvia, Lithuania, Luxemburg, Malta and Slovenia. The main reason why we do not break down these countries into regions is that data at any sub-national level are not available (from Eurostat). For the other countries, we created the custom regional breakdown with an aim to create regional units of approximately equal territorial size (although variations still exist, obviously), as well as to maximize data availability (data is less commonly available for more detailed breakdowns). In a fair amount of cases, we merged several regions to create larger entities. This was done especially in cases were regions at the particular level we are using correspond to (large) cities (and their immediate surroundings), because we do not want to mix in our analysis purely metropolitan environments with more general regions.

Thus, we are using mostly NUTS 1 level for Belgium and Germany, and mostly NUTS 2 level for Austria, Czech Republic, Spain, Finland, France, Greece, Hungary, Italy, Poland, Portugal, Sweden and Slovak Republic, and a mix between NUTS 1 and 2 for the Netherlands and the United Kingdom. The complete list of regions used is given in Appendix 3, and shown on Map 1.

Our spatial analysis involves weighting by geographical distances (we use km distances as our unit throughout the paper). Although we experimented with a wide range of weights (such as binary weights based on contiguity, nearest neighbours or threshold distance), we present results for only a single type of weights. These are based on exponential decay, and are given by the formula $w_{i j}=e^{-0.01 d_{i j}}$, where $w_{i j}$ is the spatial weight between regions $i$ and $j$, and $d_{i j}$ is the distance between the centroids of the two regions. The exponential parameter -0.01 is arbitrary, but is chosen to reflect a fairly rapid decline of the weight with distance. ${ }^{5}$ The exponential decay function is projected onto Map 1, where the range of the curve is scaled to reflect a distance of $1,000 \mathrm{~km}$. Obviously, the maximum weight is 1 (for distance 0 , or, the weight of regions with themselves), and we see that the steep decay implies that the weight drops below $1 / 2$ already for most of the nearest neighbours. At a distance of $500 \mathrm{~km}$ (which is at most 3-5 orders of contiguity), the weight becomes effectively zero.

Before we use the weights in the spatial analysis, they are standardized. Usually, we use row-standardization, which means that in a region-by-region distance matrix of the exponentially decaying weights, we divide each cell by its row sum. Thus, for each region in the analysis, the sum of weights relative to all other regions in the sample is set to zero. This effectively means that we do not make any distinction between central and more peripheral regions. In some cases (the spatial principal components analysis), we use a different standardization procedure. In this case, each cell in the

\footnotetext{
4 See http://ec.europa.eu/eurostat/ramon/nuts/home_regions_en.html.

5 Calculations with weights that decay slower generally show that spatial dependence is much lower than what is reported in this paper. Results for alternative weighting schemes are available on request.
} 


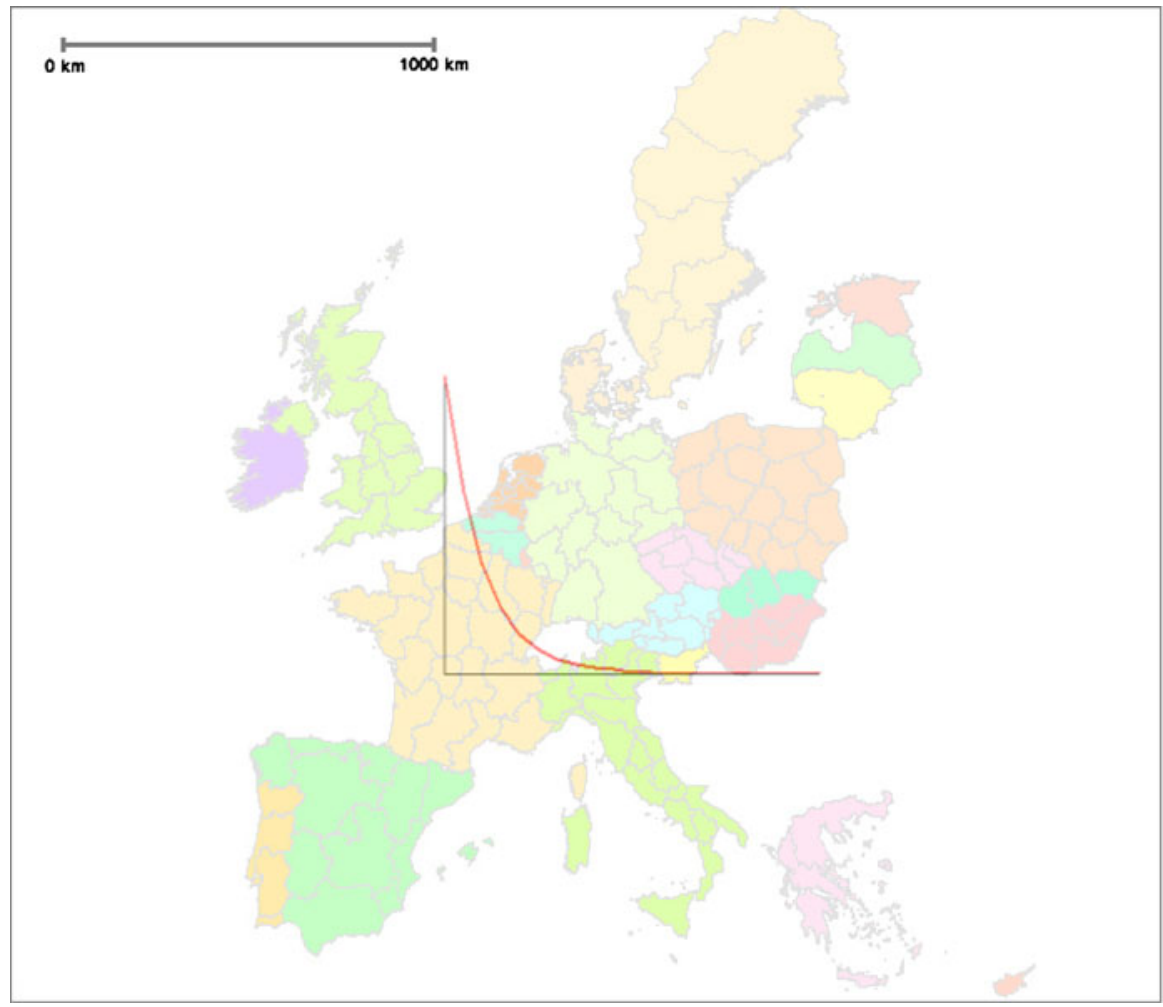

Map 1 The sample of European regions, with distance weights function (exponential decay) projected

distance matrix is divided by the matrix total, so that all cells in the matrix add to 1 . Throughout the analysis, we set the weights $w_{i i}$ to zero for all regions $i$. This means that in any spatially weighted calculation, the region itself is excluded.

\section{Data and sources}

The analysis will be based on 30 variables, which we will now briefly present. The variable names and short definitions are listed in Table $1 .^{6}$ The first three variables relate to educational levels of the population. The primary source of these data is Eurostat. The variables measure the share of people in the population aged 16-65 of a region in 2003 with high, medium or low level education. These levels are defined by Eurostat. Next, there are eight variables that measure the structural composition of a region, in terms of the share of employment in eight different sectors. These sectors are agriculture, mining, manufacturing, construction, energy and utilities, services, business services and higher education and health. The latter two sectors are sub sectors of the services sectors. Although there are a number of lower level sectors that could have been used,

$\overline{6 \text { Throughout the paper we will }}$ use the short variable names introduced here. 
Table 1 Explanation and definition of variables

\begin{tabular}{|c|c|}
\hline $\begin{array}{l}\text { Variable } \\
\text { abbreviation }\end{array}$ & Short explanation \\
\hline EDUPH03 & Persons with high level education as a percentage of population aged 16-65, 2003 \\
\hline EDUPM03 & Persons with medium level education as a percentage of population aged 16-65, 2003 \\
\hline EDUPL03 & Persons with low level education as a percentage of population aged 16-65, 2003 \\
\hline SLAGR03 & Share of agriculture in employment, 2003 \\
\hline SLMIN03 & Share of mining in employment, 2003 \\
\hline SLMAN03 & Share of manufacturing in employment, 2003 \\
\hline SLCON03 & Share of construction in employment, 2003 \\
\hline SLENR03 & Share of energy and public utilities in employment, 2003 \\
\hline SLSER03 & Share of services in employment, 2003 \\
\hline SLBUS03 & Share of business services in employment, 2003 \\
\hline SLHED03 & Share of health and education in employment, 2003 \\
\hline GDPPC02 & GDP per capita, 2002 \\
\hline AVG & Average yearly growth rate of GDP per capita, 1999-2002 \\
\hline PDENS02 & Population density, 2002 \\
\hline UPOP02 & Unemployed as a percentage of population aged 16-65 \\
\hline INPOP02 & Inactive as a percentage of population aged $16-65$ \\
\hline EPOP02 & Employed as a percentage of population aged 16-65 \\
\hline PTOT & Patent applications at EPO during 1999-2002 divided by population in 2002 \\
\hline HERF & Herfindahl index for sectoral patenting shares (1999-2002 totals) \\
\hline & $\begin{array}{l}\text { The following variables are all patent applications at EPO during 1999-2002 } \\
\text { divided by population in 2002, for individual sectors }\end{array}$ \\
\hline PEC31_34 & Resource based industries (food, textiles, wood, paper, printing, ISIC 31-34) \\
\hline PEC3522 & Pharmaceuticals (ISIC 3522) \\
\hline PEC35 & Chemicals, excl. pharmaceuticals (ISIC 35-3522) \\
\hline PEC37_8 & Metals, incl. basic metals (ISIC $37+381$ ) \\
\hline PEC3825 & Computers and office machinery (ISIC 3835) \\
\hline PEC382M & Machinery, excluding office machines and electricals (ISIC 382-3825) \\
\hline PEC3832 & Electronics (ISIC 3832) \\
\hline PEC383M & Electricals (ISIC 383-3832) \\
\hline PEC384 & Transport equipment (ISIC 384) \\
\hline PEC385 & Instruments (ISIC 385) \\
\hline PECOTH & Other industries (ISIC $36+39$ ) \\
\hline
\end{tabular}

the analysis is limited to these eight sectors because the other more detailed sectors do not seem so crucial to the relation between innovation and growth. The structural variables measure the share of a sector in employment of a region in 2003.

The next category of variables are six indicators describing the general state of economic development: GDP per capita (in PPP, using country-level deflators), the average growth rate of GDP per capita over the period 1999-2002, population density (population per square $\mathrm{km}$ ), registered unemployment (in persons) as a percentage 
of the population, employed persons as a percentage of the population, and inactive persons as a percentage of the population. All variables in this category are measured in 2002.

The remaining variables relate to patenting. These variables are based on counts of patent applications at the European Patent Office (EPO). In the data we use, patent counts are summed over the period 1999-2002 (using priority dates), and divided by population of the region in 2002 in order to account for differences in size between regions. Obviously, patenting indicators have certain disadvantages as indicators of innovation (for a discussion, see, e.g., Griliches 1990). Data on R\&D employment or expenditures are the most commonly used alternative, but in the particular case of this paper, such data are not available for the wide range of regions that is used (including the new member countries). As a result, however, our picture of innovation will be somewhat biased against those activities in technology that are more of an imitative nature, since these are better measured by $R \& D$ than by patents. However, a broad comparison to the dataset in Hollanders et al. (2008), which includes more indicators but less regions, confirms that the patent data used here broadly point in the same direction as other innovation indicators. ${ }^{7}$

The patents are assigned to regions on the basis of the reported address of the inventor. We use the Merit IPC-Isic concordance table (Van Moergastel et al. 1994) to assign patents to an economic industry. This concordance table is based on a detailed comparison of the content of the International Patent Classification and ISIC (rev. 2) classification schemes, and a matching of the activities described in both. The principle of the matching is that the patent is assigned to its most likely industry of origin (e.g., a textiles machine is assigned to the machinery sector, not the textiles sector). The concordance is done at the 4-digit IPC level, and a mixture of 2-, 3- and 4-digit ISIC industries (these will be introduced below when we discuss the data). We use only the manufacturing sectors in the concordance, and opt to aggregate the 22 sectors found in the concordance to 11 . The concordance allows the assignment of a single IPC class to multiple ISIC industries, based on a weighting scheme. This, and the fact that we assign inventor regions fractionally, implies that patents are assigned fractionally, i.e., we do not necessarily have an integer number of patents in each industry/region.

\section{Patterns of spatial correlation}

We start the empirical part of this paper by providing an overview of observed spatial correlation between the (categories of) indicators in our database. This analysis is based on the Moran coefficient of spatial correlation. The calculation of this coefficient starts from the calculation of a so-called spatial lag of a particular variable. For any region $i$, the spatial lag of variable $X$ is defined as the weighted average of the value of $X$ in all other regions in the sample, where we use the spatial weights in the

\footnotetext{
7 The inclusion of regions in the new member countries in the sample is also the reason why we do not employ patent citations. Citations typically occur at a lag of several years, and the patenting activities in the regions in the new member countries occur in substantial numbers only towards the end of the period for which the patent data are available. Hence citations are not very frequent in the dataset yet for these regions.
} 
calculation of this average. Note that because our spatial weights decay rapidly with distance, this effectively means that the spatial lag of a variable contains the average values of $X$ found in the geographical neighbourhood of the regions in the sample.

The Moran spatial correlation coefficient is defined as the correlation (measured in the usual way, i.e., Pearson correlation) between a variable $X$ and the spatial lag of variable $Y$. One common way of investigation is to look at the case $X=Y$, i.e., the correlation between a variable and its own spatial lag. But this corresponds to just the diagonal values in the spatial correlation matrix (variable by variable) that we will consider here. A high positive (negative) spatial correlation means that high values of variable $X$ tend to be surrounded by high (low) values of variable $Y$.

We calculate the Moran coefficients for all combinations of the list of 39 variables that was discussed previously. Note that by definition, and contrary to a 'normal' correlation matrix, the spatial correlation matrix is not symmetric, and hence we need to look at correlations between variables in a bi-directional way. Appendix 2 documents the full spatial correlation table, while Appendix 1 provides box plots reflecting the (non-spatially weighted) distribution of the variables. The box plots show that most variables are distributed fairly symmetrically, although there are a few that show long tails on the right side. Notably, such long tails are found for the shares of particular sectors (agriculture, mining, construction, health and education) in total employment, for the growth rate of GDP per capita, for population density (this is particularly strong), and for many of the patenting variables (total patenting, and at the sectoral level particularly electronics and computers).

Because the theoretical distribution for the Moran coefficient is hard to express, statistical significance is usually assessed using Monte Carlo analysis. In this way, the empirical distribution is obtained by permutating the actual values of the variables in the correlation over the regions a large number of times. $\mathrm{GeoDa}^{8}$ was used to calculate these standard errors. The standard deviations that we obtain using these methods are generally fairly low, so that the large majority of the coefficients in the $30 \times 30$ matrix is actually very highly significant. This means that in general, spatial correlation in the dataset is strong. In order to single out the particularly strong correlations, we look at the values that are higher or lower than 1.5 standard deviations $( \pm 0.374)$ of all $39 \times 39$ correlation coefficients.

Overall, positive correlations (58\% of the cases) are more somewhat frequent than negative correlations (42\%). There are $77(9 \%)$ pairs of variables that show a positive correlation that is higher than 0.374 , and $29(3 \%)$ pairs that have a correlation below -0.374 . Strongly positive spatial correlations are particularly frequent along the diagonal of the matrix: 17 out of 30 diagonal values $(57 \%)$ show a correlation that is higher than 0.374 . The variables with strong positive spatial correlation (along the diagonal of the correlation matrix) are the educational variables (all three levels), five of the eight sectoral employment shares variables (agriculture, construction, utilities, services, health and education), GDP per capita, the three employment variables (unemployment, inactive population, and employment, all as a $\%$ of population), 4

\footnotetext{
8 See https://www.geoda.uiuc.edu.
} 
out of 11 of the sectoral patenting per head variables (resource based industries, basic metals, machinery and other industries), and finally the patenting Herfindahl index.

Off the diagonal, positive spatial correlation is particularly frequent along the row and column of the GDP per capita, and within the patenting per head block. The patenting sectors that have high spatial correlation along the diagonal of the matrix are also the ones that are spatially correlated with each other (off the diagonal) and the economic variables. GDP per capita correlates strongly with services and in particular business services, employment, and the same patenting sectors as mentioned before.

The other strong correlations that are found off-diagonal are mostly negative. This is especially frequent for the sectoral employment shares variables (services and agriculture, and services and utilities), the general economic variables (unemployment and GDP per capita), and the education variables (low and medium level education).

\section{Drawing correlations together: spatial principal components analysis and cluster analysis}

The large spatial correlation table that we have discussed so far contains much detailed information that is only partially summarized by the focus on the correlation values that are larger or smaller than the arbitrary cut-off value of 1.5 standard deviations. This large set of correlations, and the underlying spatial patterns in the data are the revelations of the technology and economic growth relationship that we wish to outline for the EU-25. We therefore apply a method, admittedly impressionistic rather than aimed at the causal relationships, that will outline the main relationships between in the data. The method consists of two phases, the first of which is aimed at outlining the relationships between the variables, and the second step aimed at outlining the relationships between the regions.

The first step consists of the spatial principal components technique that is proposed by Wartenberg (1985). Like conventional principal components analysis, this is a way to summarize the correlation table of the variables in our analysis. The analysis works by extracting, by means of an eigenvalue decomposition of the correlation table, a number of components, or dimensions, that are linear combinations of variables. The components are found by optimizing the fraction of the total variance in the data that is accounted by them, such that the first component accounts for the largest possible fraction of total variance, the second for the largest possible fraction of the remaining variance, etc. The number of factors that is extracted is arbitrary, but we follow Wartenberg in using an eigenvalue criterion that is common in nonspatially weighted principal components analysis: all components with eigenvalues larger than one are retained. ${ }^{9}$ Thus, the only difference between the spatial principal components analysis and conventional principal components analysis is the calculation

\footnotetext{
9 In conventional principal components analysis, the diagonal of the correlation matrix contains only ones, and hence the sum of eigenvalues will be equal to the number of variables (this sum is equal to the trace of the correlation matrix). In a spatial correlation matrix, the diagonal values will generally be $<1$, and hence the sum of the extracted eigenvalues will generally be lower than in conventional analysis. By adopting the same eigenvalue criterion for selecting the number of components, we thus introduce a tendency to have fewer components as compared to a conventional analysis on the same data.
} 
of the correlation coefficients: the spatial variant uses the Moran coefficients, while conventional principal components analysis uses normal correlation coefficients. ${ }^{10}$

We extract three components representing a total of $88 \%$ of the total variance in the 30 variables. The factor loadings (coefficients in the linear combinations representing the factors) are documented in Table 2. The first component can be interpreted as a general indication of relative backwardness. High factor loadings are found for the share of agriculture in employment, and unemployment. On the other hand, strongly negative loadings are found for GDP per capita, and most of the patenting per head variables (including total patenting per head, but not patenting in ICT-related sectors, such as S3825 and S3832). This component accounts for two-thirds of the total variance, which indicates that the general development level is the major divide between regions in our dataset.

The second component is strongly dominated by differences in educational level of the labour force. A high loading is found for low level education (as a $\%$ of the population), and a low loading for medium level education. Also, the share of energy and public utilities loads high. There are few other strongly positive loadings, the share of services in employment and GDP per capita are (mild) exceptions. The patenting variables all have loadings very close to zero. The specific influence of education in this component seems to be dominated by the fact that the education variables have a strong national component. However, excluding these variables from the analysis does not influence the other results to a large extent (in that case, we extract just two components, which are very close to the first and third component documented in Table 2).

The final and third component is clearly related to urbanization. Population density has a high loading, as do education and health and business services (typically sectors found in urban environments). Manufacturing has a strongly negative loading. In this case, patenting in the ICT related sectors show a relatively high loading.

Having summarized the (spatial) variation in our 30 variables into three major dimensions, we proceed to investigate whether these three dimensions can be used to distinguish groups of regions in the EU-27 that share similar characteristics. Such groups represent 'archetypical' regional development patterns.

In order to do this, we use cluster analysis. Formally, the aim of the analysis is to obtain groups of regions that are relatively homogenous in terms of the variables that we put into the clustering procedure, but are different from the regions found in the other groups. We use the two-step clustering algorithm in SPSS to obtain groups of regions, based on the factor scores obtained using Table 2 above. The two-step clustering algorithm has as an important advantage that the number of clusters is determined on the basis of an objective criterion (we use Akaike's information criterion, AIC, which is a commonly found measure based on the entropy concept). The algorithm works by first forming a number of pre-clustering groups, and then merging these groups in a more-or-less traditional hierarchical clustering method. We perform

\footnotetext{
10 We symmetrize the spatial correlation matrix by taking the average of below and above diagonal elements before extracting the components. We also follow the normal procedure in (non-spatial) principal components analysis to rescale the eigenvectors (factor loadings) such that their sum of squares is equal to the value of the corresponding eigenvalue. This reflects the property that the obtained principal components account for the specific proportion of the variance reflected by their eigenvalue.
} 
Table 2 Spatial principal components
Factor loading with an absolute value $>0.4$ are italicized

\begin{tabular}{|c|c|c|c|}
\hline Variable & F1 & F2 & F3 \\
\hline EDUPH03 & 0.02 & 0.13 & 0.48 \\
\hline EDUPM03 & -0.05 & -0.75 & -0.22 \\
\hline EDUPL03 & 0.03 & -0.67 & 0.02 \\
\hline SLAGR03 & -0.41 & -0.09 & -0.03 \\
\hline SLMIN03 & 0.17 & -0.34 & -0.11 \\
\hline SLMAN03 & -0.21 & -0.30 & -0.44 \\
\hline SLCON03 & 0.08 & 0.29 & -0.18 \\
\hline SLENR03 & 0.22 & -0.51 & -0.26 \\
\hline SLSER03 & -0.19 & 0.28 & -0.43 \\
\hline SLBUS03 & -0.32 & 0.11 & 0.30 \\
\hline SLHED03 & 0.05 & 0.05 & -0.57 \\
\hline GDPPC02 & -0.54 & 0.28 & 0.07 \\
\hline AVG & 0.27 & 0.10 & -0.03 \\
\hline PDENS02 & -0.02 & -0.07 & -0.49 \\
\hline UPOP02 & -0.46 & -0.25 & -0.05 \\
\hline INPOP02 & 0.18 & 0.22 & -0.35 \\
\hline EPOP02 & -0.36 & -0.05 & 0.28 \\
\hline РTOT & -0.39 & -0.01 & 0.12 \\
\hline HERF & -0.31 & 0.19 & 0.10 \\
\hline PEC31_34 & -0.53 & 0.01 & 0.10 \\
\hline РEC3522 & -0.29 & -0.06 & 0.24 \\
\hline PEC35 & -0.39 & -0.06 & 0.18 \\
\hline PEC37_8 & -0.57 & -0.01 & -0.17 \\
\hline PEC3825 & -0.05 & 0.00 & 0.28 \\
\hline PEC382M & -0.54 & -0.03 & -0.09 \\
\hline PEC3832 & -0.05 & 0.00 & 0.25 \\
\hline PEC383M & -0.32 & 0.01 & 0.04 \\
\hline PEC384 & -0.42 & -0.01 & -0.13 \\
\hline PEC385 & -0.28 & 0.00 & 0.16 \\
\hline PECOTH & -0.56 & 0.00 & -0.04 \\
\hline $\begin{array}{l}\text { Variance } \\
\quad \text { (cumulative) }\end{array}$ & 0.66 & 0.79 & 0.88 \\
\hline Max & 0.46 & 0.67 & 0.57 \\
\hline Min & -0.57 & -0.75 & -0.44 \\
\hline
\end{tabular}

a Bonferroni adjusted $t$ test for differences in the mean score on the three dimensions of the clusters (centroids) relative to the total sample mean. All three dimensions show at least one cluster to be different from the sample mean, and hence we retain all three components in the cluster analysis.

We obtain four clusters of regions, of which one is relatively large, and the other three are of roughly equal size. The clusters and their mean scores on the three dimensions are shown in Table 3, Map 2 gives an overview of the clusters. Cluster 1 (the numbering is arbitrary) is a group of 29 exclusively Southern European regions that 
Table 3 Cluster centroids

\begin{tabular}{llllll}
\hline Factor label & $N$ & \multicolumn{2}{l}{ Cluster } & & \\
\cline { 3 - 6 } & & 1 & 2 & 3 & 4 \\
& & 29 & 67 & 35 & 23 \\
\hline Relative backwardness & Mean & 3.96 & -1.68 & 5.85 & -9.01 \\
& SD & $1.52^{* * *}$ & $2.38^{* * *}$ & $1.88^{* * *}$ & $4.63^{* * *}$ \\
Lower level education & Mean & 2.94 & -0.56 & -3.72 & -0.31 \\
& SD & $1.03^{* * *}$ & $1.37^{* * *}$ & $1.31^{* * *}$ & $1.22^{* * *}$ \\
Urban development & Mean & -1.32 & -0.79 & -3.61 & 4.85 \\
& SD & $0.96^{* * *}$ & $1.54^{* * *}$ & $0.87^{* * *}$ & $2.91^{* * *}$ \\
\hline
\end{tabular}

$*, * *, * * *$ Indicate significant differences (at the 10,5 and $1 \%$ level, respectively) of the cluster centroids from the total sample mean in a $t$ test with Bonferroni adjustment

score high on relative backwardness and lower level education, but low on urban development. This cluster spans the total Southern European space, with the exception of the Madrid and Barcelona regions in Spain, and the Rome (Lazio) region in Italy.

Cluster number 3 is the other cluster in the dataset that scores high on relative backwardness. This cluster exclusively comprises almost all of the regions in the so-called new member states (NMS) of the EU. The main difference to Cluster 1 is that the NMS cluster has a very much lower value on the low level education dimension (i.e., it has higher education than Cluster 1). ${ }^{11}$ For the other two dimensions, general development and urban development, it scores lower than the average, as does Cluster 1. The Prague region in the Czech Republic and the Budapest region in Hungary are the exceptions in the Eastern European space, and they are classified outside this Cluster 2.

We thus find that the NMS in Eastern Europe are rather similar to the Southern European regions, with the exception of education. This confirms the popular impression of the NMS as an area that is still underdeveloped relative to the EU frontier, but also has high potential when it comes to absorbing foreign knowledge.

The two other clusters are relatively highly developed clusters of regions, they both score significantly lower on the relative backwardness dimension. This also means that these two clusters are the ones that show relatively high patenting. Cluster 2 is the largest cluster, with 67 members. It consists of a broad set of central European regions, along with most of the United Kingdom and Ireland, and few regions in the North. They score high on general development, and low on lower education. The main thing that sets them apart from the remaining Cluster 4, is a relatively low level of urban development. The final Cluster 4 contains a geographical sub-cluster of German-Dutch regions, another sub-cluster of Danish and Swedish regions, and a

\footnotetext{
11 Given the communist history of the NMS and associated differences in education systems as compared to other EU countries, one may raise the hypothesis that education statistics in these countries are not comparable to the rest of the sample. Ammermuller et al. (2005) estimate education output functions (predicting student test scores), and find significant differences between Eastern European countries that quickly transformed their education systems after Western models, and those that did not. This suggests that our statistics, which refer to the labour force, and hence are significantly lagged with respect to education output, may in fact have a certain degree of non-comparability.
} 


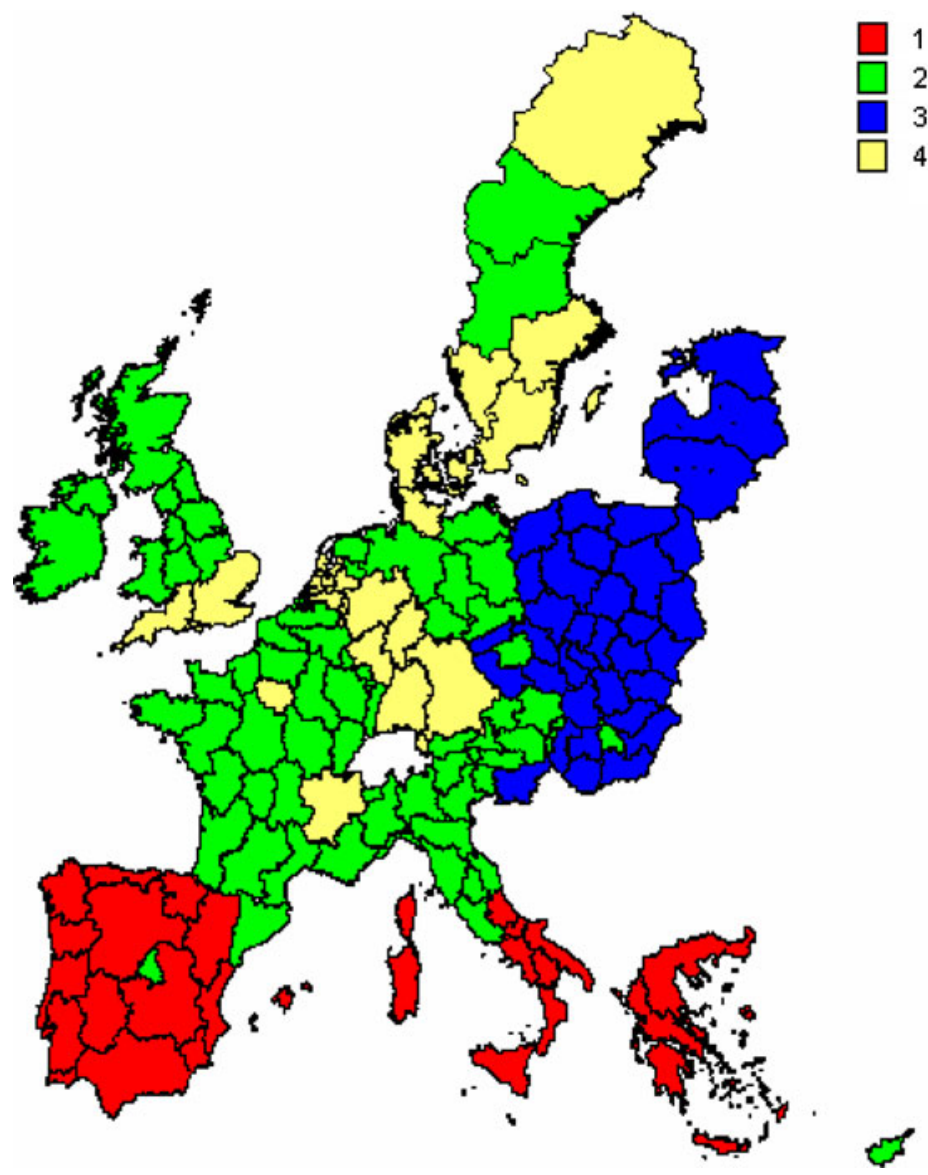

Map 2 The European regional hierarchy of technology and development (based on cluster analysis)

number of isolated highly urbanized regions (such as Paris and London). It is this final cluster that has the highest level of GDP per capita and patenting in the sample.

\section{Conclusions and outlook}

The map of European patterns of technology and economic growth that was obtained in the previous section is suggestive for a number of important tendencies at the regional European level. First of all, it suggests a major spatial divide of Europe, roughly along an "arc" running from southwest to northeast. Below this arc, i.e., in South and East Europe, we generally find regions that are at a lower general development level. The enlargement of the European Union has thus created an area that indeed deserves the attention of regional policy makers.

But of course, this is hardly an original finding, as already long before the enlargement, it was clear that the new members states were at a much lower level of GDP per capita than the "old" EU-16. The analysis here does suggest, however, that the 
Eastern European regions are different in one crucial aspect: they have a much better educated labour force than the regions in the Southern periphery of Europe. In terms of a hierarchy of economic growth and development, this puts these regions in the NMS at an advantage, because it potentially allows them to absorb foreign technology in a much more efficient way. Whether this advantage will indeed materialize, remains to be seen when new data become available.

The analysis also provides the insight that a major dividing line for innovation and growth in Europe may run along the the general level of urbanization. The outcomes of the analysis confirm the importance of urban development (e.g., Storper and Walker 1989) that has been signalled in the literature. Urban environments are capable of producing high economic growth and technological change. According to the evidence presented in this paper, it seems to be the case that urban environments are much more likely than other environments to escape the effects of a slow spatial diffusion of knowledge.

Moreover, in the most developed part of Europe, these highly urbanized regions seem to be integrated into a larger whole of spatial "corridors", which unite them with their (direct) geographical surroundings. These areas comprising one or several large cities indeed seem to function as an integrated whole, in which economic growth and technological knowledge flow quite fluently between urban centres and their sub-urban surroundings (again, Storper and Walker 1989, have pointed to such patterns).

The analysis suggests that in the South and East, such interactions have not yet emerged very frequently. Both in the South and East, major urban centres exist that take on the role of urban centres in which economic growth and innovation flourishes. Madrid, Rome and Barcelona are examples in the South that emerge from the analysis above, Prague and Budapest in the East. But what distinguishes these cities from their counterparts at the top of the spatial hierarchy, is that they do not seem to support a surrounding area within which knowledge- and economic interactions are taking place. The analysis here suggests that at this stage, the metropoles of the South and East remain isolated centres, not yet capable of generating (and using) enough spillovers.

This suggests that regional policy in these areas should be aimed specifically at such spatial interactions between large cities that already show a high level of technological potential, and their surroundings. Obviously, such a targeting of combinations of regions is at odds with the current practice of assigning Structural Development Funds, which is largely based on a number of criteria, such as GDP per capita, that relate to single regions. Thus, the policy suggestion made here is to put space into the criteria for assigning the Structural Funds.

The current analysis suggests that the current allocation mechanism runs the danger of not supporting the most promising regions in the South and the East. Instead of supporting the urban centres and the spillover effects they may have on their wider environment, the current policies run a risk of supporting the peripheral parts of the Union, where development potential is weakest. A partial reorientation of the allocation of funds towards innovation in urban centres in the South and East may be beneficial.

This is reminiscent of the discussion about equity or efficiency at the regional level that was briefly touched upon in the introduction. It has been argued (see Begg 2007 for an overview) that European regional policy at large is aimed at those regions 
where the development potential is low, and hence that it stimulates equity at the expense of efficiency. In other words, cohesion and competitiveness are competing policy goals.

By bringing space into the analysis, and into the policy criteria for assigning regional support, we may find a middle-ground in this trade-off. If regional policies are aimed at creating innovation corridors of spatially connected regions, starting at high-potential urban centres in the peripheral parts of Europe, cohesion may be stimulated at the same time that competitiveness is stimulated. Because the cohesion-policy instruments are aimed at regions where efficiency is (relatively) high. Besides the introduction of space into the criteria for the Structural Funds, such an approach would also have to include the explicit goal of creating cross-regional spillovers, and hence a change in the mix of policy instruments would be necessary.

Acknowledgments This research is part of the DIME Network sponsored under the EU 6th Framework Programme. This paper was presented at the Kiel workshop on Agglomeration and Growth In Knowledge-based Societies, 20-21 April 2007, at a seminar at IKE, University of Aalborg, DK, at the Globelics Academy, Lisbon, PT, 2-12 May 2007, at the EMAEE Conference, 17-19 May 2007 at Manchester Metropolitan University, UK, and at the Uddevalla Symposium 2007. I thank participants at these meetings, as well as two anonymous referees, for comments and suggestions.

Open Access This article is distributed under the terms of the Creative Commons Attribution Noncommercial License which permits any noncommercial use, distribution, and reproduction in any medium, provided the original author(s) and source are credited.

\section{Appendix 1: Box plots of the variables}
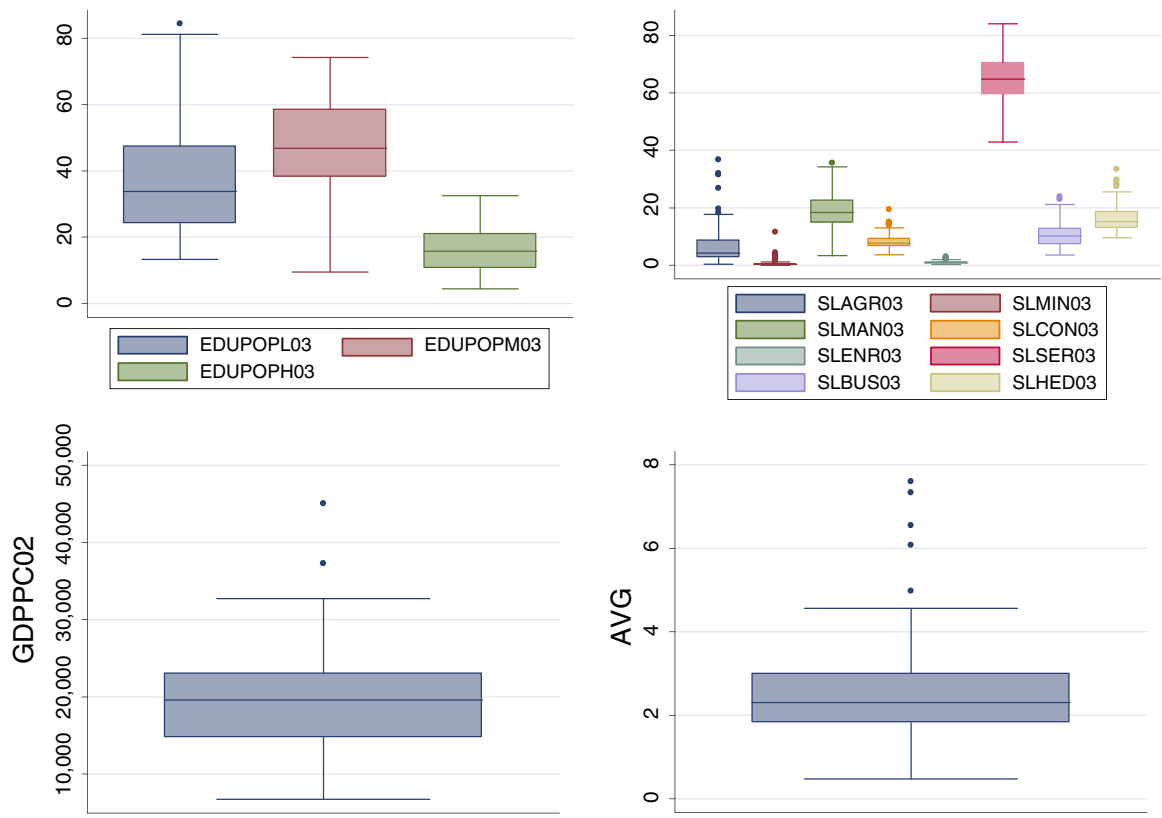

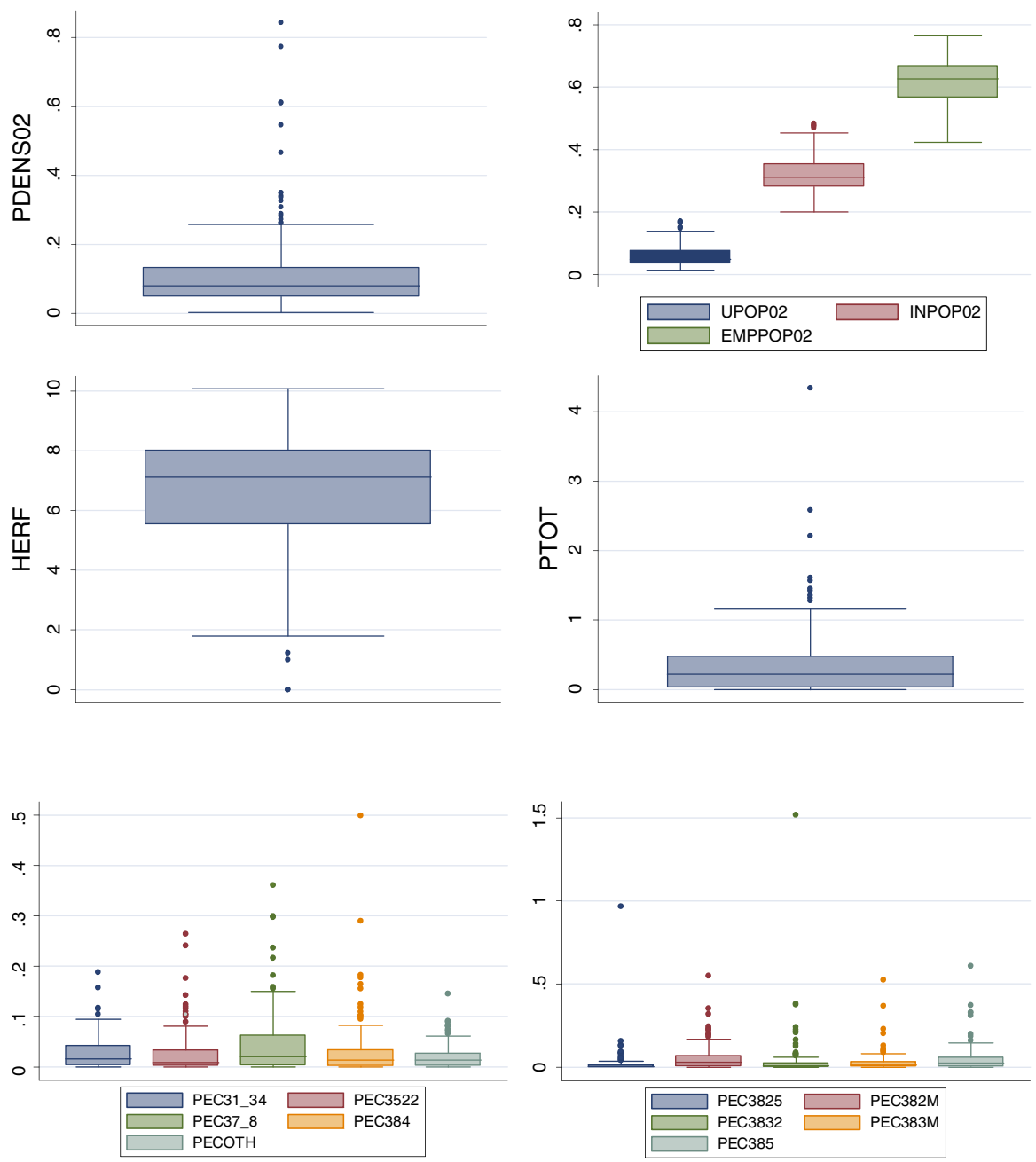


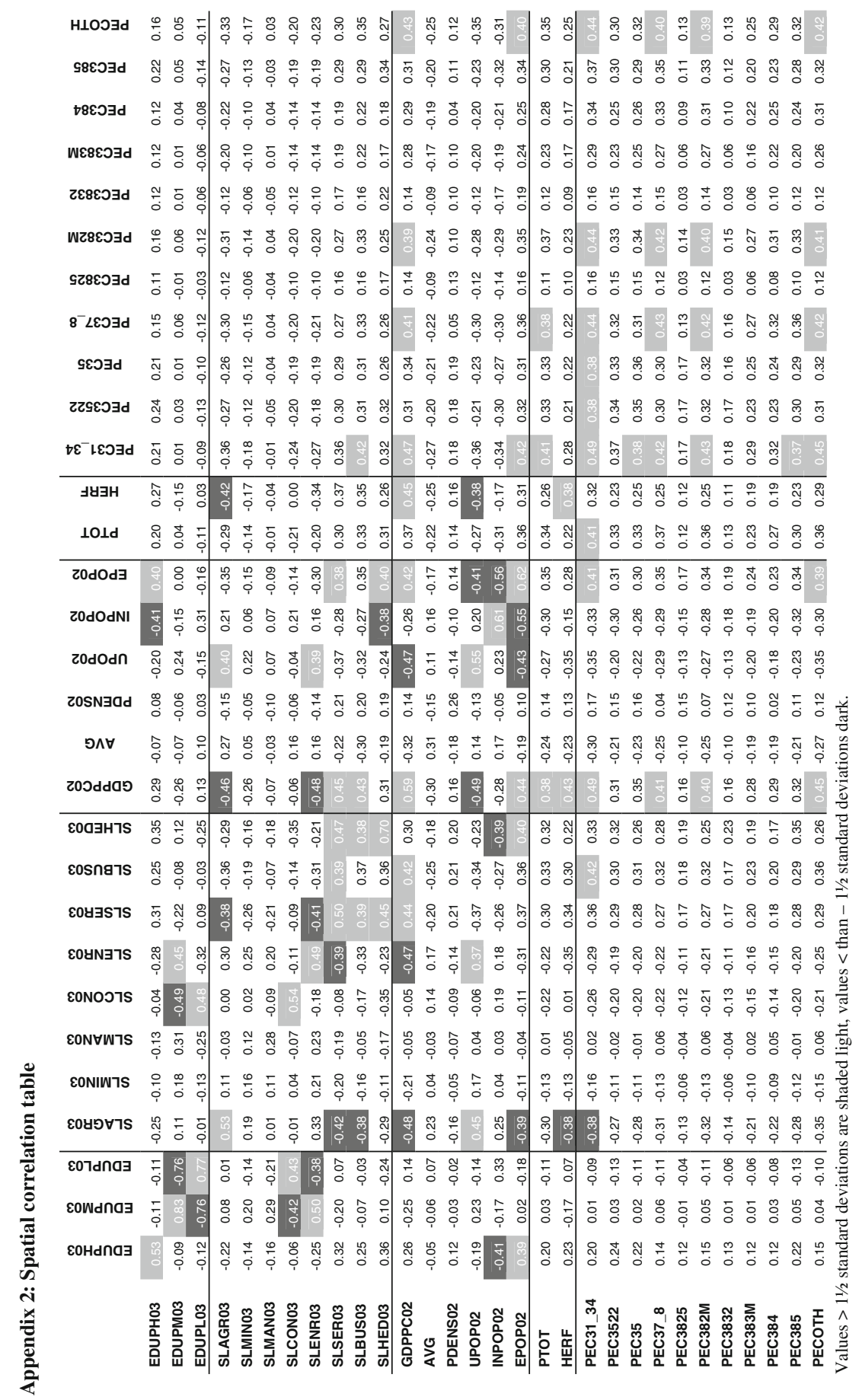




\section{Appendix 3: Regions used in the analysis}

\begin{tabular}{|c|c|c|c|}
\hline AT11 & Burgenland & ES43 & Extremadura \\
\hline AT12_13 & Niederösterreich + Vienna & ES51 & Cataluña \\
\hline AT21 & Kärnten & ES52 & Comunidad Valenciana \\
\hline AT22 & Steiermark & ES53 & Illes Balears \\
\hline AT31 & Oberösterreich & ES61 & Andalucía \\
\hline AT32 & Salzburg & ES62 & Región de Murcia \\
\hline AT33 & Tirol & FR1 & Île de France \\
\hline AT34 & Vorarlberg & FR21 & Champagne-Ardenne \\
\hline \multirow[t]{3}{*}{ BE1_2 } & Arr. Admin. & FR22 & Picardie \\
\hline & Bruxelles-Capitale, Admin. & FR23 & Haute-Normandie \\
\hline & Arr. Bruss + Vlaams & FR24 & Centre \\
\hline BE3 & Wallone & FR25 & Basse-Normandie \\
\hline CY & Kypros/Kibris & FR26 & Bourgogne \\
\hline CZ01_02 & Praha + Stredni Cechy & FR3 & Nord, Pas-de-Calais \\
\hline $\mathrm{CZ03}$ & Jihozapad & FR41 & Lorraine \\
\hline CZ04 & Severozapad & FR42 & Alsace \\
\hline CZ05 & Severovychod & FR43 & Franche-Comté \\
\hline CZ06 & Jihovychod & FR51 & Pays de la Loire \\
\hline CZ07 & Stredni Morava & FR52 & Bretagne \\
\hline CZ08 & Moravskoslezsko & FR53 & Poitou-Charentes \\
\hline DE1 & Baden-Wurttemberg & FR61 & Aquitaine \\
\hline DE2 & Bayern & FR62 & Midi-Pyrénées \\
\hline DE3_4 & Berlin + Brandenburg & FR63 & Limousin \\
\hline DE5_9 & Bremen + Niedersachsen & FR71 & Rhône-Alpes \\
\hline \multirow[t]{2}{*}{ DE6_F } & Hamburg + & FR72 & Auvergne \\
\hline & Schleswig-Holstein & FR81 & Languedoc-Roussillon \\
\hline DE7 & Hessen & FR82 & Provence-Alpes-Côte \\
\hline DE8 & Mecklenburg-Vorpommern & & d'Azur \\
\hline DEA & Nordrhein-Westfalen & FR83 & Corse \\
\hline DEB & Rheinland-Pfalz & GR1 & Voreia Ellada \\
\hline DEC & Saarland & GR2_3 & Kentriki Ellada and \\
\hline DED & Sachsen & & Attiki \\
\hline DEE & Sachsen-Anhalt & GR4 & Nisia, Aigaio, Kriti \\
\hline DEG & Thüringen & HU10 & Kozep-Magyarorszag \\
\hline DK & Denmark & HU21 & Kozep-Dunantul \\
\hline $\mathrm{EE}$ & Estonia & HU22 & Nyugat-Dunantul \\
\hline ES11 & Galicia & HU23 & Del-Dunantul \\
\hline ES12_3 & Asturias and Cantabria & HU31 & Eszak-Magyarorszag \\
\hline \multirow[t]{2}{*}{$\mathrm{ES} 21 \_2 \_3$} & País Vasco, Navarra and & HU32 & Eszak-Alfold \\
\hline & Rioja & HU33 & Del-Alfold \\
\hline $\mathrm{ES} 24$ & Aragón & $\mathrm{IE}$ & Ireland \\
\hline ES3 & Comunidad de Madrid & ITC1 & Piemonte \\
\hline ES41 & Castilla y León & ITC2 & Valle d'Aosta \\
\hline ES42 & Castilla-la Mancha & ITC3 & Liguria \\
\hline
\end{tabular}




\begin{tabular}{|c|c|c|c|}
\hline ITC4 & Lombardia & PL41 & Wielkopolskie \\
\hline ITD1_2 & Trentino-Alto Adige & PL42 & Zachodniopomorskie \\
\hline ITD3 & Veneto & PL43 & Lubuskie \\
\hline ITD4 & Friuli-Venezia Giulia & PL51 & Dolnoslaskie \\
\hline ITD5 & Emilia-Romagna & PL52 & Opolskie \\
\hline ITE1 & Toscana & PL61 & Kujawsko-Pomorskie \\
\hline ITE2 & Umbria & PL62 & Warminsko-Mazurskie \\
\hline ITE3 & Marche & PL63 & Pomorskie \\
\hline ITE4 & Lazio & PT11 & Norte \\
\hline ITF1 & Abruzzo & PT15 & Algarve \\
\hline ITF2 & Molise & PT16_17 & Centro $(\mathrm{P})+$ Lisboa \\
\hline ITF3 & Campania & PT18 & Alentejo \\
\hline ITF4 & Puglia & PT2 & Região Autónoma dos \\
\hline ITF5 & Basilicata & & Açores \\
\hline ITF6 & Calabria & SE01_2 & Stockholm and Ostra \\
\hline ITG1 & Sicilia & & Mellansverige \\
\hline ITG2 & Sardegna & SE03_9 & Sydsverige + Smaland \\
\hline LT & Lithuania & & med oarna \\
\hline \multirow[t]{2}{*}{ LU } & Luxembourg & SE06 & Norra Mellansverige \\
\hline & (Grand-Duché) & SE07 & Mellersta Norrland \\
\hline LV & Latvia & SE08 & Övre Norrland \\
\hline MT & Malta & SE5A & Västsverige \\
\hline NL1 & Noord-Nederland & SI001_2_3 & Pomurska + \\
\hline NL21 & Overijssel & & Podravska + Koroska \\
\hline NL22 & Gelderland & SI004_5_E & Osrednjeslovenska + \\
\hline NL23 & Flevoland & & Zasavska + Savinjska \\
\hline NL31 & Utrecht & SI006_A_D & Spodnjeposavska + \\
\hline NL32 & Noord-Holland & & Notranjsko-kraska + \\
\hline NL33 & Zuid-Holland & & Jugovzhodna Slov \\
\hline NL34 & Zeeland & SI009_B_C & Gorenjska + Goriska + \\
\hline NL41 & Noord-Brabant & & Obalno-kraska \\
\hline NL42 & Limburg (NL) & SK01_02 & Bratislavsky kraj + \\
\hline NO1 & Oslo og Akershus & & Zapadne Slovensko \\
\hline $\mathrm{NO} 2$ & Hedmark og Oppland & SK03 & Stredne Slovensko \\
\hline NO3 & Sør- Østlandet & SK04 & Vychodne Slovensko \\
\hline NO4 & Agder og Rogaland & UKC & North East \\
\hline NO5 & Vestlandet & UKCHI & Channel Islands \\
\hline NO6 & Trøndelag & UKD & North West \\
\hline NO7 & Nord-Norge & UKE & Yorkshire and the Humber \\
\hline PL11 & Lodzkie & UKF & East Midlands \\
\hline PL12 & Mazowieckie & UKG & West Midlands \\
\hline PL21 & Malopolskie & UKH_I_J & South East \\
\hline PL22 & Slaskie & UKK & South West \\
\hline PL31 & Lubelskie & UKL & Wales \\
\hline PL32 & Podkarpackie & UKM & Scotland \\
\hline PL33 & Swietokrzyskie & UKMAN & Isle of Man \\
\hline PL34 & Podlaskie & UKN & Northern Ireland \\
\hline
\end{tabular}




\section{References}

Abramovitz MA (1986) Catching up, forging ahead and falling behind. J Econ Hist 46:385-406

Ammermuller A, Heijke H, Wossmann L (2005) Schooling quality in Eastern Europe: educational production during transition. Econ Educ Rev 24:579-599. doi:10.1016/j.econedurev.2004.08.010

Arrow KJ (1962) Economic welfare and the allocation of resources for invention. In: Nelson RR (ed) The rate and direction of inventive activity: economic and social factors. National Bureau of Economic Research, New York, pp 609-625

Barro RJ, Sala-i-Martin X (1991) Convergence across states and regions. Brookings Pap Econ Act 22:107182. doi: $10.2307 / 2534639$

Begg I (2007) Cohesion in the EU. Structural policy and economic convergence. CESifo Forum 9:3-9

Bottazzi L, Peri G (2003) Innovation and spillovers in regions: evidence from European patent data. Eur Econ Rev 47:687-710

Breschi S, Lissoni F (2001) Knowledge spillovers and local innovation systems: a critical survey. Ind Corp Change 10:975-1005. doi:10.1093/icc/10.4.975

Caniëls MCJ, Verspagen B (2001) Barriers to knowledge spillovers and regional convergence in an evolutionary model. J Evol Econ 11:307-329. doi:10.1007/s001910100085

Cohen WM, Levinthal DA (1989) Innovation and learning: the two faces of R\&D. Econ J 99:569-596. doi: $10.2307 / 2233763$

Criscuolo P, Narula R (2008) A novel approach to national technological accumulation and absorptive capacity: aggregating Cohen and Levinthal. Eur J Dev Res 20:56-73. doi:10.1080/09578810701853181

Cuadrado-Roura JR (2001) Regional convergence in the European Union: from hypothesis to the actual trends. Ann Reg Sci 35:333-356. doi:10.1007/s001680100054

Dosi G (1988) Sources, procedures and microeconomic effects of innovation. J Econ Lit 26:1120-1171

Edler J, Kuhlmann S, Behrens M (2003) Changing governance of research and technology policy: the European research area. Edward Elgar, Cheltenham

European Commission (2001) European innovation scoreboard 2001. SEC, Luxemburg, p 1414

Fagerberg J (1994) Technology and international differences in growth rates. J Econ Lit 32:1147-1175

Fagerberg J, Verspagen B (1996) Heading for divergence? Regional growth in Europe reconsidered. J Common Mark Stud 34:431-448. doi:10.1111/j.1468-5965.1996.tb00580.x

Fagerberg J, Verspagen B, Caniëls M (1997) Technology, growth and unemployment across European regions. Reg Stud 31:457-466. doi:10.1080/00343409750132252

Frenken K, Van Oort F, Verburg T (2007) Related variety, unrelated variety and regional economic growth. Reg Stud 41:685-697. doi:10.1080/00343400601120296

Glaeser EL, Kallal H, Scheinkman J, Shleifer A (1992) Growth in cities. J Polit Econ 100:1126-1152. doi:10.1086/261856

Griliches Z (1990) Patent statistics as economic indicators: a survey. J Econ Lit 28:1661-1707

Grupp H, Mogee ME (2004) Indicators for national science and technology policy: how robust are composite indicators. Res Policy 33:1373-1384. doi:10.1016/j.respol.2004.09.007

Henderson JV (2003) Marshall's scale economies. J Urban Econ 53:1-28. doi:10.1016/ S0094-1190(02)00505-3

Hollanders H, Dunnewijk T, Wintjes R (2008) Benchmarking regions in the Enlarged Europe. In: Nauwelaers C, Wintjes R (eds) Innovation policy in Europe. Edward Elgar, Cheltenham

Jacobs J (1969) The economy of cities. Vintage, New York

Jaffe AB, Trajtenberg M, Henderson R (1993) Geographic localization of knowledge spillovers as evidenced by patent citations. Q J Econ 108:577-598. doi:10.2307/2118401

Johnson B, Lorenz E, Lundvall BA (2002) Why all this fuss about codified and tacit knowledge? Ind Corp Change 11:245-262. doi:10.1093/icc/11.2.245

Krugman P (1991) Increasing returns and economic geography. J Polit Econ 99:483-499. doi:10.1086/ 261763

Krugman P (1993) Lessons of Massachusetts for EMU. In: Torres F, Giavazzi F (eds) Adjustment and growth in the European Monetary Union Cambridge. Cambridge University Press, London, pp 241-269

Martin P, Ottaviano G (1999) Growing locations: industry location in a model of endogenous growth. Eur Econ Rev 43:281-302. doi:10.1016/S0014-2921(98)00031-2

Maurseth PB, Verspagen B (2002) Knowledge spillovers in Europe: a patent citations analysis. Scand J Econ 104:531-545 
Morgan K (2004) The exaggerated death of geography: learning, proximity and territorial innovation systems. J Econ Geogr 4:3-21. doi:10.1093/jeg/4.1.3

Storper M, Walker R (1989) The capitalist imperative. Territory, technology and industrial growth. Blackwell, Oxford

Van Moergastel T, Slabbers M, Verspagen B (1994) MERIT concordance table: IPC-ISIC (rev. 2). MERIT Research Memorandum 2/94-004, University of Maastricht

Verspagen B (1991) A new empirical approach to catching up or falling behind. Struct Change Econ Dyn 2:359-380. doi:10.1016/S0954-349X(05)80008-6

Verspagen B (1999) European 'regional clubs': do they exist, and where are they heading? On economic and technological differences between European regions. In: Adams J, Pigliaru F (eds) Economic growth and change. National and regional patterns of convergence and divergence. Edward Elgar, Cheltenham, pp 236-256

Verspagen B (2004) Innovation and economic growth. In: Fagerbergn J, Mowery DC, Nelson RR (eds) Oxford handbook of innovation. Oxford University Press, Oxford

Von Hippel E (1994) 'Sticky information' and the locus of problem solving: implications for innovation. Manage Sci 40:429-439. doi:10.1287/mnsc.40.4.429

Wartenberg D (1985) Multivariate spatial correlation: a method for exploratory geographical analysis. Geogr Anal 17:263-283

Zabala-Iturriagagoitia JM, Voigt P, Gutiérrez-Gracia A, Jiménez-Sáez F (2007) Regional innovation systems: how to assess performance. Reg Stud 41:661-672. doi:10.1080/00343400601120270 